MedieKultur | Journal of media and communication research | ISSN 1901-9726

Article - Theme section

\title{
The Datafication of Public Service Media
}

Dreams, Dilemmas and Practical Problems

A Case Study of the Implementation of Personalized

Recommendations at the Danish Public Service Media 'DR'

\section{Jannick Kirk Sørensen}

MedieKultur 2020, 69, 90-115

Published by SMID | Society of Media researchers In Denmark | www.smid.dk The online version of this text can be found open access at www.mediekultur.dk

\begin{abstract}
Historically, public service broadcasting had no quantifiable knowledge about audiences, nor a great interest in knowing them. Today, the competitive logic of the media markets encourage public service media (PSM) organizations to increase datafication. In this paper we examine how a PSM organization interprets the classic public service obligations of creating societal cohesion and diversity in the new world of key performance indicators, business rules and algorithmic parameters. The paper presents a case study of the implementation of a personalization system for the video on demand service of the Danish PSM 'DR'. Our empirical findings, based on longitudinal in-depth interviewing, indicate a long and difficult process of datafication of PSM, shaped by both the organizational path dependencies of broadcasting production and the expectations of public service broadcasting.
\end{abstract}

Keywords

Public service media, personalization, algorithmic recommendation, video on demand, public service broadcasting 


\section{Introduction}

In November 2019, the Danish public service media (PSM) organization DR took a first step into the world of datafication, more precisely algorithmically curated content selection. With the launch of a new version of their video on demand (VoD) platform DRTV, the interface changed only a little, but underneath, a new algorithmic engine introduced a very different way for editors to publish and present DR's video content. ${ }^{1}$ Alongside the classic manually curated lists of videos, the new curation platform can also present personalized selections to users, or content based on editor-defined 'business rules'. The new system introduces a change from a tradition of manually curated content presentation. The algorithmic recommendation of videos is motivated both by a change in user consumption towards video on demand and by the fast growth of DRTV's catalogue. DR's first VoD webpage, from October 2005, offered 31 videos presented under six categories. ${ }^{2}$ DRTV's current VoD offers more than 500 series and individual programmes, presented in more than 50 categories or headlines on 28 web pages. ${ }^{3}$

Both public and private TV broadcasters have over the last decades offered VoD services, but new web technologies offer new possibilities for both personalization and more detailed analysis of audience behaviour. While these features challenge both commercially funded broadcasters and licence fee-financed public service broadcasters, this article will focus on the latter. We will, however, discuss personalized VoD as a challenge for both types of TV broadcaster, as well as aspects that relate specifically to public service broadcasting. This article uses the case of the DRTV VoD service to discuss the implications, challenges and opportunities for PSM of introducing algorithmic personalization and recommendations in its publishing of content. Based on 16 semi-structured in-depth interviews with five interviewees involved with DR's personalization project, this paper discusses whether the personalization challenges or changes DR's PSM role. The interviews were conducted over a period of almost four years, from the beginning of the personalization project in late 2016 to September 2020.

The paper is structured as follows. In the theoretical part, we discuss the general challenges of datafication for broadcasters with personalization as an ambiguous strategy before we examine the specific challenges for public service broadcasters. After introducing our methodological framework, we continue by presenting and discussing our empirical findings. Finally, our conclusion summarizes the discussion and offers questions for further research.

\section{Theory}

\section{Big data and datafication as challenges for broadcasters}

For advertising-funded public service and private broadcasters, the increasing use of VoD services challenges their business strategy, including the advertising revenue model. Not only does a constantly increasing share of advertising from traditional media such as 
linear broadcasting go to interactive platforms (IAB Europe, 2019)-particularly global platforms such as YouTube, Facebook and Google—but broadcasters may also hesitate to undermine their own well-established business of channel curation and scheduling of programmes with new VoD offerings (Andersson Schwarz, 2016; Murschetz \& Prandner, 2018). The disruptive potential of the digital transformation of broadcasting was described early by the European Broadcasting Union (EBU Digital Strategy Group, 2001, 2002), along with other scholars (Chalaby \& Segell, 1999; Tadayoni \& Skouby, 1999). Broadcasters' shrinking presence in the value chain from content creation to curation and delivery was identified by Andersen Business Consulting (2002) and noted by the EU's State Aid office (EU-DG Competition, 2008, p. 3). As Johnson (2020) demonstrates, the 'appization' of TV shifts control of the TV market from broadcasters to the tech companies that control and distribute apps for smartphones and smart TVs.

When broadcasters add personalization and data analysis to their VoD services, the potential of predicting and creating audiences (Ang, 1991) grows, but the technologies present also broadcasters with a number of dilemmas. Big data can be used as a tool for audience insights, but Murschetz and Prandner (2018, p. 60) comment that "the strength of digital technologies, be it social, mobile, big data analytics, or cloud computing, does not lie within these technologies individually. Instead, it consists of how broadcasters integrate them to transform their organizational processes and business models". The data are thus not enough: it is the catalysing effect for business decisions (e.g. commissioning and publication of content) that matters (Erevelles et al., 2016). Personalization-the key instrument to create valuable data about consumer preferences-constitutes a marketing problem for broadcasters, however, and an identity problem for one of the broadcasters most valuable assets, the curated channel brand. Over decades, broadcasters have built strong channel brands via carefully planned channel portfolios and strategic scheduling of programmes (Lassen, 2018, 2020). The first generation of VoD-the category-based hierarchical catch-up or archive services-with its programme categories constituted a deviation from the classic channel-oriented presentation of TV programming but often maintained a reference to the brand of the original broadcasting channel. The second generation-algorithmically generated personalized VoD recommendations-challenges the channel structure and forces the broadcaster either to strengthen the master brand, create new types of channel, or innovate the branding relationship with users. The future of TV channel brands is thus open.

\section{The ambiguities of personalization}

The concept of personalization lends itself to many interpretations as it is applied in many different contexts (Fan \& Poole, 2006). It may indicate ownership or emotions; it may promise customer sovereignty (Rosen, 2004; Schipper, 2002), but also protection against information overload (Mitchell, 2005; Tidline, 1999), which can be perceived as paternal- 
istic (Tintarev \& Masthoff, 2015). It is thus often unclear who controls or performs the personalization - the individual user or a (digital) service provider (Milano et al., 2019) and whose interests are served (Brey, 2005; Carlson, 2006).

Personalization can be understood either as an explicit way to suggest relevancy to a user (with or without an underlying advanced algorithm) or as an implicit or hidden algorithmic method to present content to the user that is assumed to be more likely watched than other content (Bredies et al., 2007; Thurman \& Schifferes, 2012). In this article, we define personalization as the algorithmic recommendation process that produces interfaces (content suggestions, such as lists) that are different among users. The algorithmic recommendation may be: 1) based on user profile information, such as usage history (Kang et al., 2016) -i.e. used for collaborative filtering (Aggarwal, 2016c); 2) based on properties of the video content, such as topic, genre, country of origin, length, cast or similar, stored as metadata description and used for content-based filtering (Aggarwal, 2016a); or 3) context-based filtering, based on, for example, the user's device (e.g. small smartphone screen or big $4 \mathrm{~K}$ TV), the time of the day/week/year, the location of the user (commuting/at home, in a specific city or region) and other properties of the use context (Adomavicius \& Tuzhilin, 2015; Aggarwal, 2016b). Other forms of recommendation, such as personality-based recommendations (Tkalcic \& Chen, 2015), are possible, as any data signal can, in theory, be combined to calculate a recommendation.

The personalization of media interfaces offered on, for example, newspapers' websites not only aims to increase the 'stickiness' of the site to keep visitors browsing longer and thereby exposing them to more commercial ads, but also to generate better data about the user to reduce the media company's dependence on external suppliers of user data (Thurman \& Schifferes, 2012, p. 776). The personalization of commercial media interfaces such as newspaper websites is thus not only a question of improving the user experience and attempting to increase the relevance of the content to respond to social media sites' algorithmic principles of content selection, but also an important tool for traditional publishers in their efforts to prevent losing more advertising revenue to social media and tech platforms by keeping the user data in-house (Bodó, 2019; Thurman \& Schifferes, 2012). News personalization thus has clear business objectives that reflect the turn towards automated journalism which challenges a classic professional ideal-journalists as the core in democratic deliberative/enlightenment processes (Milosavljević \& Vobič, 2019, pp. 1101-1102). Algorithmic personalization introduces other criteria of relevance that challenge traditional notions of the public sphere, leading to concerns of emerging filter bubbles of like-minded citizens (Sunstein, 2001, 2007) and a general scepticism by letting commercial algorithms - or rather, the tech platforms using them-be in charge of information, enlightenment, entertainment and opinion-building (Pariser, 2011). In the context of traditional media, some of these filter bubble concerns can be refuted, however. Human editors are sometimes more biased than algorithms (Möller et al., 2018; see also Bernstein et al., 2020; Bodó et al., 2019). Borgesius et al. (2016), like other researchers, 
find no actual evidence of filter bubbles. However, the request for transparency of algorithms (Diakopoulos, 2016; Wieringa, 2020; Zarsky, 2013) and the possibility to inspect and change algorithmic decisions (Citron \& Pasquale, 2014; Milosavljević \& Vobič, 2019) could lead to a higher level of accountability being expected of public service broadcasting (PSB) and public service media (PSM) institutions (Sørensen et al., 2020).

Personalization often implies collecting and analysing user behaviour data. Broadcasters using personalization may thus participate in what Zuboff (2019) terms "surveillance capitalism". This new form of capitalism is not only global and unregulated, but it also centralizes power. But the participation is on unequal terms. Even large broadcasters have little power compared to the predictive consumer insights possessed by central actors in the surveillance ecosystem. Broadcasters can accumulate data about user behaviour on their own platform, but they do not, as the platforms have the ability to track users and capture data signals across different websites (Lerner et al., 2016; Roesner et al., 2012) and devices (Acar et al., 2014). This implies less information about the user, affecting both pricing for advertising and the predictive power of audience analysis and trend spotting. The famous Netflix method of letting big data on user behaviour inform the innovation of new TV shows (Lycett, 2013) may be difficult for many broadcasters to use (Day, 2011). In the case of big data and personalization, PSB/PSM use of the technologies may trigger questions about user data privacy (Sørensen \& Van den Bulck, 2018; Sørensen et al., 2020).

\section{Datafication and public service media}

Researching how public service broadcasters approach online distribution in a more competitive and internationalized market of VoD content, Donders (2019, p. 1012) finds that "[ $t]$ he online strategies of some public broadcasters are directionless, although others, admittedly, have developed more mature schemes." She characterizes PSB organizations' transition to PSM in five phases (Ibid., p. 1013): 1) the experimental phase, where "public broadcasters realize that the Internet offers possibilities to distribute content in a different manner"; 2) the panic phase, "when public broadcasters realise that other companies or even some private individuals are more successful than they are at attracting audience attention online. This tends to result in directionless strategies, aimed largely at channelling audiences to their websites." The panic phase resembles PSBs in the 1980s being confronted with commercial competition; 3) the expansionist phase, "in which the public broadcasters aim to maximise their presence online, placing more value on this than on their public service mission"; 4) the consolidation phase, where PSBs confronted with budget cuts must prioritize online activities and focus on satisfying the public interest in media, achieved through offering "quality on-demand services" (ibid. p. 1013) and through internal reorganization. Budgets for non-linear distributions are also increased; and finally, 5) the maturity phase, "when public broadcasters have managed to develop an online strategy that focuses on the public service proposition of each of their brands, combined 
with a solid view of how to connect with the audience. By this stage, public broadcasters have become more conscious of the need for competitive trade-offs with, for example, Netflix, YouTube or Twitter."

For public service broadcasters, the decisions and investments needed to launch VoD services and other digital services were thus not necessarily slowed down by a fear of losing advertising revenue or changing business models, as in the case of commercial to private broadcasters (Murschetz \& Prandner, 2018), but were, as Donders (2019) shows, dependent on both internal organizational dynamics and the media political situation in the respective countries with regard to the PSB online/PSM remit. As an example, DR has been allowed teleservice-based services since 2000 (Kulturministeriet, 2000, \$7 stk. 3), and since 2001 'internet' has been stated as a distribution mode on same footing as 'radio' and 'TV' (Kulturministeriet, 2001, \$6a). Conversely, German PSBs have only very limited possibilities for services that are not directly related to broadcasting activities (Schweizer \& Puppis, 2018). The media political and regulatory conditions for PSM online services and the understanding of 'public value' are thus different in different European countries (Moe, 2008).

As identified early by the European Broadcasting Union's (EBU) Digital Strategy Group (2002), a transformation from the transmission-oriented public service broadcasting to the distribution-neutral public service media was necessary to sustain the purpose of public service in a digital, now IP-based media environment. One could also, with Bolin's (2004) observation of public service's capability of transformation and "eternal resurrection" (ibid. p. 285), see the shift to PSM as organizational survival. We hold, however, that the existence of PSB and PSM institutions is a result not only of the ability to adapt to new market and media political conditions, but also because the ideals of PSB/PSM and the praxis of these organizations constitute an important contribution to the coherence and wellbeing of deliberative democracies (Syvertsen, 2003). Jakubowicz (2007, p. 30) sees it as a chance for "a new beginning", but one that requires that the "ideological objections" centred on the public funding model of PSB are countered, as it is proven that PSB is still needed although "[C]ommercial media are said to offer 'limitless choice'; that the "broadcasting" in PSB is replaced with "media" or even just content, as in "public service content"; that the legitimacy problem of the license fee is solved; and that the "service" remit of PSB is modernized and its relationship with the public "put on a new footing". In other words, only the core of PSB should remain (Jakubowicz, 2006).

Keeping the core, however, begs the question of what the core consists of. One possibility is obviously to refer to normative ideals of PSB (UNESCO, 2001), but, as argued by Nissen (2006), the programming policies of both PSB and PSM must navigate between reaching as many persons in the population as possible to show societal relevance, but with the danger of being accused of unfair competition, and showing distinctiveness in the programming by addressing not only the PSB ideals but also more specific media political obligations, as expressed in public service contracts and similar. This balance might be sought by "mimicking" popular commercial formats (Andersson Schwarz, 2016, 
p. 131), by using the lead-in strategies for broadcast scheduling (Tiedge \& Ksobiech, 1986), by audience measurement, and now also by adopting algorithmic personalization. When asked, PSM organizations may admit that they use these tools, techniques or services, but immediately add that the tools, techniques and services are reinterpreted and modified for the context of PSB.

On a practical level, shaping the actual datafication of PSM organizations, the EBU has for a couple of years hosted the Big Data Initiative (EBU, 2016, 2017). Through conferences and workshops, PSB managers, editors and data scientists have exchanged views regarding policies and the use of big data systems for content recommendation, trend prediction and audience behaviour analysis, among others. A 2018 EBU report offers the EBU's view on big data and datafication. The use and implementation of big data, such as algorithmic recommender systems and personalization, have attracted some attention among researchers. Pöchhacker et al. $(2017,2018)$, with help of ethnography in the tradition of science and technology studies, analysed the development of an algorithmic recommender service for the VoD service of German public service broadcaster Bayerische Rundfunk (BR). The design process is influenced by requirements in German constitutional law. That, along with the Rundfunkstaatsvertrag (Broadcast Law) stipulates the traditional PBS values such as unbiased programming, objectivity and diversity. These values must be expressed in the design and configuration of a recommender system (Pöchhacker et al., 2017, p. 3; Schmidt et al., 2018), such as an algorithmic understanding of diversity (Eickhoff, 2017).

Álvarez et al. (2020) present an overview of the personalization of public service VoD services by analysing the interfaces of 56 PSM in Europe, concluding that 16 VoD interfaces have "some type of suggestion or recommendation to visualize content, either it being through a 'we recommend..., or a more specific 'recommended for u..."' (Álvarez et al., 2020, p. 728). Álvarez et al. (2020) distinguish between three ways that personalization is presented in the wording of the headline/title: 1) "Direct appeal to the spectator: 'we advise you watch', 'recommended for you', 'have you seen this?', 'you can't miss this', 'options for you', 'recommendations for you'"; 2) "On behalf of the PSM: 'it's worth watching', 'watch this week', 'recommended emissions', 'we recommend', 'our selection'”; and 3) "Content oriented: 'binge from the start', 'popular', 'highlighted', 'more seen', 'daily topic', 'something new to watch', 'more recently seen'” (Álvarez et al., 2020, p. 729). Using this method, it is difficult to determine whether these 'recommendations' are the results of algorithmic processes or are just equipped with the headline 'we recommend' or similar without being different from one user to another. Similarly, the method of interface analysis does not allow detection of content that has been algorithmically selected based on a user profile or another variable but not presented as such to the user (see also López-Golán, 2019).

Andersson Schwarz (2016) analyses data-driven personalization at the Swedish PSBs SVT and SR, observing that "the adherence to broadcasting" is "a principal attribute of these organizations", creating "friction" "or institutional resistance" (p.125) in the transition to become PSM organizations. This friction also affects the personalization of VoD 
systems. According to Andersson Schwarz (2016, p. 137), the Swedish PSB is "premised on majoritarian appeal, both in its legacy ethos and in the bulk of its programming", which means that "SVT is not likely to embrace full-scale personalization. Rather, innovations that divulge such a move should primarily be thought of as a form of "image management" (ibid., p. 136). It is more important for Swedish PSBs to achieve national legitimacy through a majoritarian appeal than to optimize audience ratings. Discussing "the difficulties of assessing diversity as a quantifiable quota" (ibid., p. 137), as suggested in Helberger's (2011) concept of 'diversity by design'-for example, managed by algorithms (Helberger, 2012)_Andersson Schwarz (2016, p. 137) asks: "Can a PSB be majoritarian, ostensibly populist, while still containing elements that promote diversity in a qualitative sense?" This points to the paradox of personalization of public service broadcasting.

Based on interviews with editors, project leaders and technical staff, Sørensen (2019) compares how nine different European PSB organizations implement algorithmic recommendations. Based on technical and business-oriented questions to respondents regarding the implementation processes, a number of dilemmas are identified where PSB ideals and requirements clash with the industry praxis of recommender systems. 1) Login policies challenge PSB traditional values. Based on the principle of universal access (Van den Bulck \& Moe, 2018), public service broadcasters have traditionally offered programming free-to-air. With a user login, personalized VoD can provide better recommendations and audience data, however. Problems related to cookie consent can also be mitigated. 2) Metadata are key to the production of recommendations (de Gemmis et al., 2015). For the transformation to data-driven media companies (Pellegrini, 2017), useful semantic metadata are essential, but the metadata produced for broadcasting are not very suitable for algorithmic recommendation. 3) Detailed audience data allow new more detailed key performance indicators. But what should guide the recommender systems and management decisions? How does the idea of key performance indicators relate to the concept of public service broadcasting? 4) Reflecting diversity in the programming is a core obligation in the PSB remit (UNESCO, 2001), but how is that obligation understood in the context of personalized recommendations? Should a "diversity diet" (Sørensen \& Schmidt, 2016) be enforced? 5) The mode of algorithmic recommendations relocates editorial decisions from humans to algorithms (Milosavljević \& Vobič, 2019). How is this transformation implemented in the PSM organization? 6) The recommender systems and connected systems require either the building of technical knowledge within the organization or the purchase of an external solution. The latter can make the PSB organization more dependent on external business partners (Lindskow, 2016), which in turn may conflict with PSB core values (Sørensen \& Hutchinson, 2018), while the former requires an interdisciplinary knowledge exchange in the PSB organization, as computer scientists and editors must find a common language to define and develop the system (Ehn, 1988; Pöchhacker et al., 2018). 


\section{Research question}

The research shows us tensions related to the datafication of broadcasters in general and public service broadcasters in particular, as well ambiguities in the concept of personalization. The recommender systems thus produce a number of dilemmas for both public service broadcasters and private broadcasters. Based on this, we ask:

- To what extent are the dilemmas of datafication a product of public service broadcasting as a distinct normative media form?

- To what extent does the algorithmic praxis of PSB - its materialization-conflict with the ideals and norms associated with PSB?

By answering these questions the paper contributes to formulating the fundamental tensions between the concept of personalization as seen from commercial contexts and public service broadcasting as praxis, tradition and ideals. The paper thus problematizes the datafication of public service broadcasting by distinguishing between public service broadcasting in particular and broadcasting in general.

\section{Methodology}

The case of DRTV's implementation of personalization and algorithmic curation software is analysed from the point of view of public service studies as presented above, but through the lens of the materiality of ICT (Leonardi, 2012). We examine the relations between public service ideals and strategic intentions on the one side and, on the other side, the constraints and possibilities embedded in these technologies. This approach enables us to analyse whether the new software serves as a neutral instrument for DR's publishing activities or transforms these activities. With Harris and Henderson (1999) and Hutchby (2001), we assume that technologies have 'preferred readings' inscribed in their structure. We therefore do not subscribe to the idea espoused by, for example, Löwgren and Stolterman (2004) that digital technology is a malleable design material without properties. We believe that the path dependencies in software development and the global dominance of ICT over other communication technologies (Henten \& Tadayoni, 2008, 2015) effectively define the use of IT in, for example, PSM organizations.

As our main empirical source, we use in-depth interviewing (Kvale, 2007). Between December 2016 and September 2020, we conducted 16 semi-structured interviews with the project leader and project staff from the DRTV personalization project. The longitudinal span of interviews allows all phases of a classic ICT development and implementation process to be represented (Sommerville, 2010). Following this process, additional interviews were conducted with DR staff, such as the Head of Scheduling, as they had been involved in or assigned to the project. Interviewees were recruited with the help of snowball sampling (Morgan, 2008). The 16 in-depth semi-structured interviews (see Table 1) followed a question guide that was informed by the author's survey of implementation recommender systems at other European PSBs, where seven dilemmas were identi- 


\begin{tabular}{|c|c|}
\hline Name and position & Interview number, date, length, type \\
\hline Jakob Faarvang, & \#1: 22 December 2016, $90 \mathrm{~min}$, face-to-face \\
\hline \multirow{2}{*}{ Head of the DR personalization project } & \#2: 27 February 2017, 1h 15min, face-to-face \\
\hline & \#3: 6 June 2017, 1h 21min, face-to-face \\
\hline From autumn 2018: & \#4: 27 February 2018, 41 min, telephone \\
\hline \multirow[t]{3}{*}{ Head of Product Management } & \#5: 25 April 2018, 30min, telephone \\
\hline & \#6: 28 August 2018, 10min, telephone \\
\hline & \#7: 13 November 2018, 2h 13min, face-to-face \\
\hline Ulrik Dornonville de la Cour, & \#1: 13 November 2018, 2h 13min, face-to-face \\
\hline \multirow[t]{2}{*}{ Analyst. } & \#2: 21 August 2019, 1h 52, face-to-face \\
\hline & \#3: 18 December 2019, 54min, face-to-face \\
\hline From January 2020: & \#4: 9 June 2020, 58min, telephone \\
\hline DevOps \& QA & \#5: 14 September 2020, 61min, telephone \\
\hline Mads Nilsson, UX designer & \#1: 23 July 2019, 1h 21min, face-to-face \\
\hline Søren Gjelstrup Jessen, & \#1: 20 May 2020, 58min, telephone \\
\hline Specialist in Optimization & \#2: 9 June 2020, 58min, telephone \\
\hline and Personalization & \#3: 15 September 2020, 1h25min, telephone \\
\hline $\begin{array}{l}\text { Henrik Faurby Birck, } \\
\text { Head of Scheduling }\end{array}$ & \#1: 5 June 2020,59min, telephone \\
\hline
\end{tabular}

Table 1: List of interviews and interviewees

fied (Sørensen, 2019), by other previous research and by the literature. As interviewees included domain-field experts and managers, a confrontative/agonistic interviewing style (Kvale, 2007, pp. 75-76) was applied to provoke the discursive development of arguments related to high-level PSB value questions, while other parts of the interviews had a narrative form (Kvale, 2007, pp. 72-74). The audio-recorded interviews were transcribed and topic coded (Olszewski et al., 2007). The first reading of the interviews searched for signs of PSM personalization dilemmas (Sørensen, 2013, 2019, 2020; Sørensen \& Hutchinson, 2018; Sørensen \& Van den Bulck, 2018). In the second reading of the interviews, emerging topics/problems/dilemmas were sought. In the third reading, interview statements were related to the wider literature search.

\section{Findings}

Reflecting the literature review and the related research, we present our findings under four thematic headings that span across the organization. We focus on recurring issues in interviews indicating either structural problems or dilemmas in the encounter between DR's praxis and the materiality of the algorithmic systems. The four thematic headings are: 1) a publisher's need for control; 2) algorithmic content exposure; 3) controlling the black box; and 4) the materiality of public service recommendations: metadata and cookies. 


\section{A publisher's need for control}

The relaunched DRTV VoD service is described by project leader Jakob Faarvang ${ }^{4}$ as part of DR's personalization project. The personalization project is organizationally placed at the managerial level of DR Media, DR's commission unit responsible for planning and buying content. The purpose of personalizing DRTV is to improve the user experience of DRTV, Faarvang explains (Interview \#1). A report commissioned by DR found that other VoD services used by DR's users provide better (personalized) recommendations and provided a better user experience-for example, helping the user find the content-than DRTV's existing VoD service. Introducing recommender systems in an organization centred on human curation and public service values is a sensitive issue, however. To demonstrate the effect of algorithmic personalization on management and editors without risking jeopardizing DR's appearance and 'tone of voice', experiments were conducted in the early project phase on less exposed text-based web pages of the DR.dk site. These initial experiments showed a remarkable increase in the click-through-rate (CTR) for the personalized recommendations and proved the potential of personalization. However, an increased CTR is not an objective in its own right, Faarvang states (Interview \#2). The new system should also address DR's problem of exposing its large and growing catalogue of video titles.

DRTV's expert in analysis and optimization Søren Gjelstrup Jessen explains (Interview \#3) that as of September 2020, the DRTV VoD front page contains only one fully personalized row based on the user's viewing history. It is only shown to logged-in users. The other rows on the DRTV front page are either editorially curated but sorted algorithmically, or entirely manually curated. Algorithmic sorting prioritizes the content according to the user's assumed preferences (based on his/her viewing history). Finally, in some rows, such as the top page rows, all contents' position is manually curated, or locked for the first and second video item. Head of Scheduling (Danish: Planredaktionschef) Henrik Birch states that for the foreseeable future DRTV schedulers would like to retain manual control of the exposure, particularly of the upper part of the DRTV VoD front page-the top video rows (Birch, Interview \#1). Søren Gjelstrup Jessen anticipates that more rows will be automated in the future, but a higher number of personalized rows is not an explicit goal. When the personalized recommendations start to render recommendations as precise and interesting as the editorially composed rows, more rows can be personalized (Gjelstrup Jessen, Interview \#3). Gjelstrup Jessen assumes that top page rows will remain human-curated for a long time (Interview \#1). On a regular basis, editors of DR's scheduling department decide which rows to show and whether these should be personalized in one way or another. The number of personalized rows thus changes over time. On three of the channel pages (DR1, DR2, DR3) and on thematic pages of DRTV, more personalized rows are shown at the top of the page. ${ }^{5}$ The channel or universe aimed at older kids, DR Ultra, features a generic recommendation at the top of the page titled 'Ultra anbefaler' (translated as 'Ultra recommends'). The channel or universe for younger kids, DR Ramasjang, does not label any of its content as 'Recommendation'. On the video playback pages, both content-based and 
collaborative recommendations are shown to the user. When a video has finished playing, three video items of related content (via content-based filtering) are shown.

The idea of using an algorithmic decision-making system in the context of a PSB organization such as DR produces normative tensions. The well-established principle in public service broadcasting of editorial control could come under pressure when content is selected and exposed to individual users based on computer calculations (Sørensen \& Hutchinson, 2018). In his second interview, Jacob Faarvang stressed that the algorithm will not be allowed to dominate publication or exposure for "the foreseeable future": "We are a house of editors. We will not for the foreseeable future let the algorithm drive the exposure. We would lose our identity. What would be our livelihood?" (Faarvang, Interview \#2). The more advanced business rules and segment-oriented personalization tools may be too big a step for DR now, but they are ready-to-use "when the organization is ready", as Faarvang puts it. Later, in 2020, Faarvang sees the algorithm and its potential for segmenting as part of a transformation process where the algorithm supports DR's publishing by being both more relevant to the users and still fulfilling DR's editorial intentions (personal communication, 2 October 2020).

An external provider of the curation and personalization platform was chosen after a public tender. Faarvang (Interview \#2) presents the software from the TV personalization company Think Analytics as more than an algorithmic recommender system, namely a flexible tool for curating and publishing. It offers a number of manual and semi-automated ways to determine which content to show to which users when. The choice of a curation tool instead of a classic algorithmic personalization tool can be seen as a strategic decision: the configurability of the TV curation tool satisfies the organization's need for control regarding the appearance and exposure of DR's content; deviation from the known and proved human curation of DRTV should be as little as possible.

\section{Algorithmic content exposure}

Diversity in programming is central to the scheduling of flow TV (Lassen, 2018, 2020) as well as general value of PSB (UNESCO, 2001). The limited space of the computer screen offers a challenge for PSB websites in displaying a diverse range of programmes, however. This suggests personalization as a solution, but at the same time it introduces a tension between what is regarded as personal and what is regarded as public (Sørensen, 2011). The way diversity is aimed for in the algorithmic or manual exposure of content is thus a relevant question in the case of DRTV. The interviewees agree with the importance of diversity but do not initially imagine an algorithm to ensure diversity. Diversity is well represented by DR's catalogue of programmes, but the presentation in the interface influences viewing. Programmes at the top of the page are more likely to be viewed than others, and programmes shown on the visible left side of the page are also more likely to be watched. While the previous software for DRTV presented the sequence for all users, 
the new software can optimize the sequence according to the assumed interests of the user, which may result in a more broad exposure of the content.

The potential of a content presentation not centred on flow channels has for a long time been acknowledged by DR. Based on data analysis of users' viewing behaviour at DRTV, clusters of programmes from different channels, and sometimes targeted different segments, were identified early (Faarvang, Interview \#1). An algorithmic recommender system would be capable of innovating the content exposure, but how to interpret the requirement of diversity in this context? Jakob Faarvang states in interview \#2, that the idea of the recommender system is not necessarily to move the user from one category of content to another, such as from popular music to news, but to expose the user to content from a neighbouring segment of users, identified though data analysis of users' viewing patters (so-called 'clustering'). But defining and measuring diversity, or broadness, for it to become operational for DRTV is methodologically difficult, Jakob Faarvang states (Interview \#5): "Broadness could be that you watch different content, specific programmes, but it could also be different genres or content from different thematic collections". The definition of diversity in the context of PSB is thus non-trivial (Sørensen \& Schmidt, 2016).

\section{Controlling the black box}

While other PSM organizations have developed their own systems (Pöchhacker et al., 2017; Sørensen, 2019), DR has chosen an external provider. The intention was to speed up the process of implementation and, as Jakob Faarvang explains: "We are not a technology house-we are content people". DR has a policy of outsourcing the infrastructure service delivery (Faarvang, Interview \#1). Faarvang (Interview \#3) stresses that the personalization project is driven by strategic goals, not by technology; thus it makes sense to outsource the delivery of the personalization. As of September 2020, the DRTV front-end (user interface) is provided by Massive (owned by Deltatre ${ }^{6}$ ); the content is hosted and streamed by the global CDN provider Akamai; ' cookie consents are administrated by Cookiebot.com; on-page marketing campaigns are provided by smartadserver.com; and the personalization is by Think Analytics. ${ }^{8}$ Starting with Sky TV, Think Analytics has a track record of about 20 years of TV recommendation for commercial broadcasting, "helping the world's largest TV and OTT operators maximize customer value and loyalty".' Commercial TV providers such as Sky, Virgin Media and Deutsche Telekom are listed as customers, and the BBC is reported to use Think Analytics. While DR's choice of an external provider places the burden of the technical delivery outside DR, where does the editorial work end and the algorithm start? In the case of Think Analytics, parts of its system are confidential, but does one need algorithmic transparency (Sandvig et al., 2014) to control what is presented to the users? Head of Planning Henrik Birck thinks that black-box algorithmic secrecy is not optimal for the required transparency of PSM operations, but acknowledges it as a condition for using recommender systems (Interview \#1). The black-box problem 
would also occur with an internally developed software, Faarvang points out (personal communication, July 2020). Understanding the causes and effects of the algorithm is a challenge in both cases. The need for control in the case of DRTV, however, is addressed by employing an expert. Søren Gjelstrup Jessen is employed to configure the system, including the personalized recommendation lists. The other traditional DRTV schedulers continue to prepare the other 20 or more lists via the traditional publishing tool (Gjelstrup Jessen, Interview \#1). More recently, a scheduling editor has been appointed as editorially responsible for personalization at DRTV (Gjelstrup Jessen, Interview \#3).

\section{The materiality of public service recommendations}

When algorithmic recommendation is brought from idea to realization, the materiality of the technology becomes manifest. The practical reality poses obstacles to the vision. In the case of DRTV, the technical-practical world becomes manifest in three ways: 1) through the metadata that describe the content; 2) through user data created via the user's viewing behaviour; and 3) through privacy-protecting regulation and technologies.

Detailed metadata about video programming is a prerequisite for both content-based recommendations and content exposure based on business rules (de Gemmis et al., 2015). However, the generation or collection of quality metadata which are suitable for algorithmic recommendation is a recurrent problem among public service broadcasters (Sørensen, 2019). Traditionally, metadata have been produced for the purpose of commissioning and auditing broadcasting content. DR uses the EBU hierarchical metadata categorization ESCORT/Tech 3322 (EBU, 2007) when budgets are made and programmes are commissioned at DR. EBU categories like 'Sports' or 'Non-fiction/information' and sub-level categories like 'Athletics' or 'News and current affairs' are assigned to planned content. These metadata are also used for the yearly 'Public Service redegørelse', the contractually required public service value statement. These administrative metadata categories may not always produce relevant recommendations, however, or may even result in 'noise' in the form of incomprehensible recommendations (Gjelstrup Jessen, Interview \#3). One reason might be wrongly categorized content, as the EBU metadata system is vast and difficult to understand. Another reason might be the creative development a programme undergoes from idea to final video: the final programme may possess qualities that are important for users but that were not reflected in the original idea. Once assigned, however, it is difficult to change the EBU categorization, not only for practical reasons but also due to a strong tradition of categorization. The programme may thus not be well exposed in the recommender system. The broadcasting administrative purposes of the metadata thus conflict with the intention of improving the user experience of the VoD system. Experimentally, a new metadata categorization purposed for the recommender system will be tested, Søren Gjelstrup Jessen (Interview \#3) explains. Another challenge is the mapping of DR's metadata categories with those used by the personaliza- 
tion platform Think Analytics. A testing tool allows editors to see how Think Analytics classifies specific content, however, and a wrong mapping can be corrected. Dornonville reports (Interview \#5) that DR has full insight into how the mapping of DR's EBU-based metadata to Think Analytics' categories takes place. Both the metadata categories and the video content synopsis text are analysed by Think Analytics. Discrepancies between metadata, description and actual viewing experience (the content) may sometimes lead to odd recommendations, Søren Gjelstrup Jessen (Interview \#3) explains.

The materiality of algorithmic personalization is also manifest via the effects of the GDPR and of privacy-enhancing browsers such as Google Chrome, Safari and Firefox. Dornonville (Interview \#5) reports that as of autumn 2020, about 40 pct. of users were skipping or rejecting the cookies which are necessary to provide personalization. An alternative to cookies is user logins, but only a fraction of users choose to log into DRTV. For a public service VoD service like DRTV without a mandatory login functionality, it is therefore difficult to build up precise data. The missing user profile data means fewer data for the algorithm to work with. Furthermore, user profile data are currently deleted after 30 days to reduce the costs of running the algorithm, but also to keep recommendations up to date. The sparseness of data may result in, for example, a rarely viewed programme may be less exposed in the algorithm due to the sparseness of user data. Due to the limited user profile/cookie data, and to avoid low quality recommendations, DR has currently chosen to show fewer personalized rows. Increasing the number of logged-in users is thus of strategic importance for DR, according to Dornonville (Interview\#5).

\section{Discussion}

Some of DRTV's challenges are tightly connected to DR's status as a public service broadcaster, while others apply to broadcasters in general. We observe that Johnson's (2020) notion of 'appization' also applies in the case of DRTV: the datafication process subjects DR to the logic of 'appization' - the existing operations must be adjusted to fit to the demands of datafication in terms of, for example, the type of metadata needed or the dependency on user behaviour data. In this respect, the conditions for datafication are the same for DR as a PSB as for any other broadcaster. DR's engagement with datafication particularly can also be explained as a reaction to its shrinking influence in the audio-visual value chain. Appization and datafication are necessary for survival. DR's need to control the 'tone' of its appearance, including in the algorithmic recommendation, reflects its publicist background shared with other public and private editorial media. In this light, the algorithms will probably only be used to assist publishing for a long foreseeable future. DR has the above-mentioned problems in common with many other broadcasters, both private and public, and even with publishers in general. Other problems are specific to public service broadcasting, either due to the regulation that guides the PSB/ PSM activities or due to the core values that characterize and have partly legitimized PSB 
since its beginning. In the following, we discuss the case of DRTV, but the problems may be relevant to other public service broadcasting organizations.

\section{Algorithms and PSB diversity}

Diversity is a key concept in public service (UNESCO, 2001). In both the current public service contract (Kulturministeriet, 2018) and in earlier regulation, it is represented through the Danish words alsidig and mangfoldig. The translation of these words is challenging, but alsidig can be translated to versatile, all-round, many-sided and comprehensive, while mangfoldig translates as multiple, manifold, multi-faceted and diverse. ${ }^{10}$ In the current public service contract (Kulturministeriet, 2018), DR is obliged to "give all citizens free access to a comprehensive and diverse content which in an unbiased way supports the citizens' capacity in participating the Danish democracy and strengthens Danish culture and language" (ibid., p. 1, my translation ${ }^{11}$ ). The regulatory request, as well as DR's aim to provide a multi-faceted array of programming, is mostly approached by the interviewees as content diversity (Napoli, 2011) in terms of the diversity of content made available to viewers/users and the sources used. Napoli (2011) contrasts this traditional sender-oriented understanding of diversity with his new proposed exposure diversity which refers to "a focus on the nature of the content and sources actually consumed by media users" (ibid., p. 246). Helberger (2012) even suggests that exposure diversity be produced by algorithmic recommender systems (see also Sørensen \& Schmidt, 2016).

Algorithmic recommendation such as personalization contains the possibility of expanding the user's interest but also the reinforcement of existing interests, possibly leading to "filter bubbles" (Pariser, 2011). The purpose of one of the first commercial recommender systems, Amazon's item-to-item-based system (Linden et al., 2003), was to increase the user's interest, more specifically the cross-selling of items. Diversity in personalized e-commerce recommendation is thus about expanding users' interests (Castells et al., 2015). As Zhang (2008, p. 72) observes: "[The l]aw of diminishing marginal returns also tells us that recommendation diversity can make more profit for the producers". Computer scientists thus search for optimal mathematical solutions to diversity in the display of items (Kaminskas \& Bridge, 2016; Kunaver \& Požrl, 2017; Zanitti et al., 2018). Also, VoD recommender systems like Think Analytics (used by DRTV) address diversity as a commercial problem, here anchored in pay channel-centric thinking: Think Analytics asserts that its system "can balance strong consumer-centric objectives with ... the business's marketing objectives".12 However, in a public service context, diversity has a slightly different meaning from in e-commerce. Viewpoint diversity (Helberger, 2012) is a core prerequisite, essential for PSB's contribution to a well-functioning public sphere and its political legitimacy. The PSB ideal thus calls for a specific form of diversity that may or may not be modelled in a recommender system (Sørensen \& Schmidt, 2016). The above-mentioned balance between expansion and reinforcement of users' interests is thus a challenging question in the PSB context. On the one hand, the programming as a whole must reflect 
diversity; on the other hand, niche channels, for example, have been built to increase the predictability of the experience. With personalized VoD interfaces, the problem which emerged with the introduction of niche flow TV and radio channels is amplified: personalized VoD could be envisioned as a very narrow niche channel, but it could also be optimized for a high level of diversity. Still, we need a machine-readable definition of diversity that reflects PSB values. The algorithmic recommendation, when adjusted to avoid emerging filter bubbles, could be used to echo the thoughts and principles developed by the BBC's first Director General John Reith, who required that PSB should give people what they did not know they wanted (Reith, 1924), or, even more radically in a speech in July 1930: "The best way to give the public what it wants is to reject the express policy of giving the public what it wants" (quoted in Bailey, 2007, p. 108). It is unlikely that this strategy for diversity will be successful in today's saturated media landscape, but when formulating policies for diversity in the context of personalized VoD, we need to consider both the balance between the expected and the unexpected, and the balance between editorial intentions and user behaviour.

\section{Transparency, PSM and algorithms}

With Bucher (2018), we understand algorithms as socio-technical constructions, but we also observe that algorithmic decisions, particularly when based of series of processed data, are difficult to explain within a simple cause and effect scheme. Thus we observe two discussions related to the control of DRTV's personalization. One discussion concerns the tactical and technical knowledge needed to understand the output of the recommender system in relation to the input and data processing, making hypotheses about causes and effects; another discussion regards insight into an external proprietary system. The first discussion applies to all organizations that apply algorithmic systems: specialist knowledge is needed to control the systems, and management must therefore trust the technical employees to control the system according to company values. The second discussion is more complicated, as the core questions here are: To what level of detail can a customer (here, DR) claim technical insights from a company (Think Analytics)? When do these insights matter for the customer (DR)? And when is the transparency of public interest (Gillespie, 2014)? While the outsourcing of public ICT services calls for a general discussion (Schuppan, 2009) and the control of infrastructure for public service media in particular (Henten \& Tadayoni, 2020), we focus here specifically on control and transparency of the algorithmic recommendations. As DR delegates decisions to algorithms run by another entity, Think Analytics, a discussion on algorithmic transparency and control formally emerges here. But before we draw any conclusions, we need to elaborate on what 'controlling' a recommender system means. We can identify different aspects and different layers.

In the core of most recommender systems we will find the same two basic algorithmic principles: content-based filtering (Aggarwal, 2016a) and collaborative filtering (Aggarwal, 2016c). The mathematics are the same regardless of the purpose and ownership of 
the recommender system. The mix between content-based and collaborative filtering presented to users could be discussed through the lens of a normative public service ideal: if a public service VoD is understood as just a repository or archive, and if the audience aspect (the popularity of the content) is disregarded, one could argue for a purely content-based recommendation (provided quality metadata are available). However, we could also at least theoretically argue for collaborative filtering contributing to (societal) coherence, as it connects users and content otherwise disconnected.

At the next level, the configuration, the purpose is to adjust the parameters, including the mix between content-based and collaborative filtering, to produce relevant recommendations. The question, worthy of further research, is whether 'relevant recommendations' are fundamentally different in a public service context compared to a commercial $\mathrm{VoD}$ ? At the level of configuration, ownership of the software is less important than the possibility of adjusting the parameters, and the policies for doing so. Finally, as we have seen above, the metadata determine how content-based recommendations should be made. Control-understood as the transparency of algorithms, configuration and, not least, data-is difficult to isolate and capture. It is difficult to provide detailed explanations of algorithmic recommendations as they result from a series of data processes. The output of the algorithm is defined by what is fed in-the semantic metadata of the video content, the user viewing behaviour and the business rules. A great deal of complexity thus emerges when control of PSB algorithmic recommendations is discussed.

\section{Privacy, tracking and cookies}

In October 2019, the EU High Court ruled in the so-called Planet 49 case $^{13}$ that passive cookie consent is illegal. The user must provide active consent-for example, via a click in a checkbox. But as discussed by Sørensen et al. (2020), it may not be enough for PSM to comply with GDPR. As "islands of trust" in the media landscape (Sørensen \& Van den Bulck, 2018, p. 5) users/citizens may expect public service media not to participate in the "surveillance capitalism" eco-system (Zuboff, 2019). Furthermore, as discussed by Sørensen (2020), the datafication of PSB/PSM implies that they risk abandoning the classic value proposition of universalism, where programming is made available to all via broadcasting as a gift without any expectations in return (Scannell, 2005). Ironically, the sparseness of user profile data in the recommender system may also provide an obstacle to the core mission of PSB - to inform and enlighten in a diverse way; the lack of data makes it more difficult to find and show the topical - semantic connections between different programmes through the algorithm.

\section{Conclusion}

As of September 2020, only a small part of the DRTV VoD interface was personalized. DR takes careful steps when personalizing. Personalization is not a goal in itself, but rather 
an instrument to facilitate an improved user experience. The personalization of DRTV is also DR's first step in the datafication of its operations, with hopes of becoming a more efficient, competitive and modern media organization. As discussed above, the troubles along the journey were not only of a practical character, but are also an expression of the tensions inherent in the materialization of the idea of algorithmic public service recommendations. One important materialization is the metadata problem. Another, more fundamental problem is the lack of an operational definition of diversity in the context of PSB. Finally, we see that datafication is also slowed by external changes to the user data ecosystem. Browsers' blocking of trackers, the requirements posed by GDPR and dynamics of surveillance capitalism all work against the intentions of PSB personalization. Most importantly, though, the historical roots of PSB, its obligations and its role in the media landscape shape and slow the adoption of personalization. The commercial concept of personalization does not translate very well to the idea of a public institution.

Arguably PSB needs personalization in order to appear attractive and modern to at least parts of its audience. But PSB needs personalization in a form other than that in the commercial context. Personalization needs to be adapted to PBS, but how is still unclear. Concerns about unleashing a black-box algorithm on the public service have been addressed through the configurability of the curation tool. The editors remain in control of the $\mathrm{VoD}$, but the prerequisites for mastering the algorithm lie at a more complex level, in the metadata indexing and the mapping of related concepts in the recommender system. The future of VoD curation may imply a more abstract logic, particularly if more advanced forms of personalization are applied. We therefore argue that the perception of control is rather associated with the tacit world of publishing, scheduling and editorial processes than with business rules, metadata and algorithms.

\section{Notes}

1 The DRTV Video on Demand interface/service is available not only as a browser-based website but also as apps for smartphones, tablets etc. When we refer to DRTV VoD or DRTV, we do not refer to a device-specific interface. When we refer to DR.dk/drtv, we refer to the browser-based version.

2 https://web.archive.org/web/20051013054836/http://www.dr.dk:80/drdkTV/html/nettv.asp

3 https://www.dr.dk/drtv/a-aa

4 Jakob Faarvang was promoted to Head of Product Management for all DR's digital products in autumn 2018. However, we here refer to the positions he held when the respective interviews were conducted.

5 As of 20 September 2020, 12 thematic or channel pages features a list titled 'Recommended to you'. These pages are: 'DR1', 'DR2', 'DR3', 'Dokumentar', 'Fiktionsserier', 'Natur,' 'Livsstil,' 'Kultur', 'Viden', 'Historie', 'Musik', 'Anbefalinger.' 'Anbefalinger' shows a personalized list plus a list composed of content from the entire catalogue. Thirteen sub-pages do not have a list with personalized recommendations as indicated in the interface: 'Film', 'Humor og Satire', 'Nyheder \& Debat', 'Underholdning,' 'Sport', 
'Krimi', '2. Verdenskrig', 'A- $\AA$ ', 'Senest tilføjet', 'Bingewatching', 'Sidste chance', and the two children's pages 'Ultra' (except 'Ultra anbefaler') and 'Ramasjang'.

6 https://www.deltatre.com accessed 2020-09-17

7 https://www.akamai.com/uk/en/

8 When loading a randomly selected video content page at DRTV (https://www.dr.dk/drtv/serie/familien-loewander_197617), the user is asked for consent to 257 different cookies from 19 external companies (Cookiebot, New Relic, Microsoft, VWO, Akamai, Infogram, Enetscores, Riddle, nexus.ensighten. com, Cxense, Smart Adserver, Adobe Inc, Peytzmail, Kantar Gallup, Gracenote, Gemius, Facebook, Twitter Inc., Massive / Daltatre) and DR.

9 https://thinkanalytics.com, accessed 2020-06-08

10 https://www.ordbogen.com/en/search\#/auto/ordbogen-daen/alsidig and https://www.ordbogen.com/ en/search\# /auto/ordbogen-daen/mangfoldigt

11 "DR skal give alle borgere fri adgang til et mangfoldigt og alsidigt indhold, der upartisk understøtter borgernes handleevne i det danske folkestyre og styrker dansk kultur og sprog."

12 "Flexible Business Rules give you control over your operational analytics environment, allowing business and customer centric rules to be captured, managed and applied both online and in batch. This ensures the system can balance strong consumer centric objectives with those of the business's marketing objectives. The Think Analytics Recommendations engine provides prioritisation of content through the use of the fully flexible Business Rules Management System. The flexible business rules engine can be used to define a variety of rules to filter, prioritise, and promote as required." https:// thinkanalytics.com/thinkrecommendations/ accessed 2020-06-08

13 EU Court case C-673/17 http://curia.europa.eu/juris/document/document.jsf?text=\&docid=218462\& pagelndex $=0 \&$ doclang $=E N \&$ mode $=$ req $\&$ dir $=\& o c c=$ first $\&$ part $=1 \& c i d=1447493$

\section{References}

Acar, G., Eubank, C., Englehardt, S., Juarez, M., Narayanan, A., \& Diaz, C. (2014). The web never forgets: Persistent tracking mechanisms in the wild. Proceedings of the 2014 ACM SIGSAC Conference on Computer and Communications Security - CCS '14, 674-689. ACM Press. doi:10.1145/2660267.2660347

Adomavicius, G., \& Tuzhilin, A. (2015). Context-aware recommender systems. In C.C. Aggarwal (Ed.), Recommender systems handbook (pp. 191-226). Springer US. http://link.springer.com/10.1007/978-14899-7637-6_6

Aggarwal, C.C. (2016a). Content-based recommender systems. In C.C. Aggarwal (Ed.), Recommender systems (pp. 139-166). Springer International Publishing. http://link.springer.com/10.1007/978-3-31929659-3_4

Aggarwal, C.C. (2016b). Context-sensitive recommender systems. In C.C. Aggarwal (Ed.), Recommender systems (pp. 255-281). Springer International Publishing. http://link.springer.com/10.1007/978-3-31929659-3_8

Aggarwal, C.C. (2016c). Neighborhood-based collaborative filtering. In C.C. Aggarwal (Ed.), Recommender Systems (pp. 29-70). Springer International Publishing. http://link.springer.com/10.1007/978-3-31929659-3_2

Álvarez, M.V., López, J.M.T., \& Ruíz, M.J.U. (2020). What are you offering? An overview of VODs and recommender systems in European public service media. In Á. Rocha, C. Ferrás, C.E. Montenegro Marin, \& V.H. Medina García (Eds.), Information technology and systems (pp. 725-732). Springer International Publishing. https://doi.org/10.1007/978-3-030-40690-5_69 
Andersen Business Consulting. (2002). Outlook of the development of technologies and markets for the European audio-visual sector up to 2010. European Commission for Information Society and Media. http://ec.europa.eu/comm/avpolicy/docs/library/studies/finalised/tvoutlook/tvoutlook_finalrep.pdf

Andersson Schwarz, J. (2016). Public service broadcasting and data-driven personalization: A view from Sweden. Television \& New Media, 17(2), 124-141. doi:10.1177/1527476415616193

Ang, I. (1991). Desperately seeking the audience. Routledge.

Bailey, M. (2007). Rethinking public service broadcasting: The historical limits to publicness. In R. Butsch (Ed.), Media and public spheres (pp. 96-108). Palgrave MacMillan. https://doi.org/10.1057/ 9780230206359_8

Bernstein, A., de Vreese, C., Helberger, N., Schulz, W., Zweig, K., Baden, C., ... Zueger, T. (2020). Diversity in news recommendations. ArXiv:2005.09495 [Cs]. http://arxiv.org/abs/2005.09495

Bodó, B. (2019). Selling news to audiences: A qualitative inquiry into the emerging logics of algorithmic news personalization in European quality news media. Digital Journalism, 7(8), 1-22. doi:10.1080/21670 811.2019.1624185

Bodó, B., Helberger, N., Eskens, S., \& Möller, J. (2019). Interested in diversity: The role of user attitudes, algorithmic feedback loops, and policy in news personalization. Digital Journalism, 7(2), 206-229. doi:1 $0.1080 / 21670811.2018 .1521292$

Bolin, G. (2004). The value of being public service: The shifting of power relations in Swedish television production. Media, Culture \& Society, 26(2), 277-287. doi:10.1177/0163443704041178

Borgesius, F.J.Z., Trilling, D., Möller, J., Bodó, B., de Vreese, C.H., \& Helberger, N. (2016). Should we worry about filter bubbles? Internet Policy Review, 5(1), 16. doi:10.14763/2016.1.401

Bredies, K., Joost, G., \& Chow, R. (2007). Designing personalized intelligent user interfaces. Presented at the IASDR 07 Conference. Retrieved from http://www.sd.polyu.edu.hk/iasdr/proceeding/papers/Designing Personalized Intelligent User Interfaces.pdf, https://doi.org/10.1145/1216295.1216305

Brey, P. (2005). Freedom and privacy in ambient intelligence. Ethics and Information Technology, 7(3), 157-166. doi:10.1007/s10676-006-0005-3

Bucher, T. (2018). If ... then: Algorithmic power and politics. Oxford University Press.

Carlson, M. (2006). Tapping into TiVo: Digital video recorders and the transition from schedules to surveillance in television. New Media \& Society, 8(1), 97-115. doi:10.1177/1461444806059877

Castells, P., Hurley, N.J., \& Vargas, S. (2015). Novelty and diversity in recommender systems. In F. Ricci, L. Rokach, \& B. Shapira (Eds.), Recommender systems handbook (pp. 881-918). Springer US. doi:10.1007/978-1-4899-7637-6_26

Chalaby, J.K., \& Segell, G. (1999). The broadcasting media in the age of risk: The advent of digital television. New Media \& Society, 1(3), 351-368. doi:10.1177/14614449922225627

Citron, D.K., \& Pasquale, F. A. (2014). The scored society: Due process for automated predictions. Washington Law Review, 89(1), 1.

Day, G.S. (2011). Closing the marketing capabilities gap. Journal of Marketing, 75, 183-195. doi:10.1509/ jmkg.75.4.183

de Gemmis, M., Lops, P., Musto, C., Narducci, F., \& Semeraro, G. (2015). Semantics-aware content-based recommender systems. In F. Ricci, L. Rokach, \& B. Shapira (Eds.), Recommender systems handbook (pp. 119-159). Springer US. http://link.springer.com/10.1007/978-1-4899-7637-6_4

Diakopoulos, N. (2016). Accountability in algorithmic decision making. Communications of the ACM, 59(2). doi: $10.1145 / 2844110$

Donders, K. (2019). Public service media beyond the digital hype: Distribution strategies in a platform era. Media, Culture \& Society, 41(7), 1011-1028. doi:10.1177/0163443719857616 
European Broadcasting Union. (2007). ESCORT 2007 EBU system of classification of radio and television programmes. http://www.ebu.ch/CMSimages/en/tec_doc_t3322-2007_tcm6-52544.pdf

European Broadcasting Union. (2016). Big Data Initiative workshop: Algorithms and society. Retrieved from https://www.ebu.ch/contents/events/2016/12/big-data-initiative-workshop-algorithms-and-society. html

European Broadcasting Union. (2017). EBU Big Data Conference 2017. Retrieved from https://www.ebu.ch/ events/2017/03/big-data-week

European Broadcasting Union. (2018). Big Data Initiative activity report 2017-2018. European Broadcasting Union. Retrieved from https://www.ebu.ch/publications/ activity-report/login_only/activity-report/ big-data-initiative-activity-report-2017-18, https://doi.org/10.15358/1613-0669-2019-2-12

European Broadcasting Union Digital Strategy Group. (2001). Media with a progressive purpose: Conclusions of the EBU Digital Strategy Group, part 2: Managing digital evolution.

European Broadcasting Union Digital Strategy Group. (2002). Media with a purpose-Public service broadcasting in the digital era. The report of the Digital Strategy Group of the European Broadcasting Union. EBU. Retrieved from http://www.ebu.ch/CMS images/en/DSG_final_report_E_tcm6-5090.pdf, https://doi.org/10.4135/9781412952606.n155

Ehn, P. (1988). Work-oriented design of computer artifacts. Arbejdslivscentrum.

Eickhoff, V. (2017). The role of diversity in recommender systems for public broadcasters. Retrieved from https://ebu.io/organizations/blog/58/17/2017/04/27/the-role-of-diversity-in-recommender-systems-forpublic-broadcasters

Erevelles, S., Fukawa, N., \& Swayne, L. (2016). Big data consumer analytics and the transformation of marketing. Journal of Business Research, 69(2), 897-904. doi:10.1016/j.jbusres.2015.07.001

EU-DG Competition. (2008). Review of the broadcasting communication summary of the replies to the public consultation. Working paper. State Aid office, DG Competition, European Commission. Retrieved from http://ec.europa.eu/comm/competition/state_aid/reform/comments_broadcasting/ summary.pdf, https://doi.org/10.1093/he/9780198725053.003.0021

Fan, H., \& Poole, M.S. (2006). What is personalization? Perspectives on the design and implementation of personalization in information systems. Journal of Organizational Computing and Electronic Commerce, 16(3-4), 179-202. doi:10.1080/10919392.2006.9681199

Gillespie, T. (2014). The relevance of algorithms. In T. Gillespie, P. J. Boczkowski, \& K. A. Foot (Eds.), Media technologies (pp. 167-194). The MIT Press. doi:10.7551/mitpress/9780262525374.003.0009

Harris, J., \& Henderson, A. (1999). A better mythology for system design. Proceedings of the CHI '99 Conference on Human Factors in Computing Systems: The CHI is the Limit, Pittsburgh, PA, May 15-20 1999 (pp. 88-95). ACM Press. doi:10.1145/302979.303003

Helberger, N. (2011). Diversity by design. Journal of Information Policy, 1, 441-469.

Helberger, N. (2012). Exposure diversity as a policy goal. Journal of Media Law, 4(1), 65-92. doi:10.5235/175776312802483880

Henten, A., \& Tadayoni, R. (2008). The impact of the internet on media technology, platforms and innovation. In L. Küng, R. Picard, \& R. Towse (Eds.), Internet and the mass media (pp. 45-64). Sage. https://doi. org/10.4135/9781446216316.n3

Henten, A., \& Tadayoni, R. (2015). The dominance of the IT industry in a converging ICT ecosystem. In H. Mitomo, H. Fuke, \& E. Bohlin (Eds.), Smart revolution towards the sustainable digital society (pp. 15-34). Edward Elgar Publishing. https://doi.org/10.4337/9781784710040.00008

Henten, A., \& Tadayoni, R. (2020). Fading public control of audio-visual media. 22. 14-17 June 2020.

Hutchby, I. (2001). Technologies, texts and affordances. Sociology, 35(2), 441-456. doi:10.1177/ s0038038501000219 
IAB Europe. (2019). European digital advertising market exceeds $€ 55$ bn in 2018. Retrieved from https:// www.iabeurope.eu/all-news/press-releases/european-digital-advertising-market-exceeds-e55bnin-2018/

Jakubowicz, K. (2006). Keep the essence, change (almost) everything else: Redefining PSB for the 21st century. In I. Banerjee \& K. Seneviratne (Eds.), Public service broadcasting in the age of globalization. Asian Media Information and Communication Centre, Nanyang Technological University School of Communication and Information.

Jakubowicz, K. (2007). Public service broadcasting in the 21st century. What chance for a new beginning? In G.F. Lowe \& J. Bardoel (Eds.), From public service broadcasting to public service media (pp. 29-49). Nordicom, Göteborg Universitet. https://doi.org/10.1177/02673231090240030502

Johnson, C. (2020). The appisation of television: TV apps, discoverability and the software, device and platform ecologies of the internet era. Critical Studies in Television: The International Journal of Television Studies, 15(2), 165-182. doi:10.1177/1749602020911823

Kaminskas, M., \& Bridge, D. (2016). Diversity, serendipity, novelty, and coverage. ACM Transactions on Interactive Intelligent Systems, 7(1), 1-42. doi:10.1145/2926720

Kang, G., Tang, M., Liu, J., Liu, X., \& Cao, B. (2016). Diversifying web service recommendation results via exploring service usage history. IEEE Transactions on Services Computing, 9(4), 566-579. doi:10.1109/ TSC.2015.2415807

Kulturministeriet. (2000). Bekendtgørelse af lov om radio: Og fjernsynsvirksomhed (Radio-TV-loven).

Kulturministeriet. (2001). Bekendtgørelse af lov om radio: Og fjernsynsvirksomhed.

Kulturministeriet. (2018). DR's public service-kontrakt for 2019-2023.

Kunaver, M., \& Požrl, T. (2017). Diversity in recommender systems: A survey. Knowledge-Based Systems, 123, 154-162. doi:10.1016/j.knosys.2017.02.009

Kvale, S. (2007). Doing interviews. Sage.

Lassen, J.M.M. (2018). DRs tv-virksomhed i forandring: Programflade, portefølje og platforme. Retrieved from https://static-curis.ku.dk/portal/files/209265845/Ph.d._afhandling_2018_Lassen.pdf

Lassen, J.M. (2020). Multichannel strategy, universalism, and the challenge of audience fragmentation. In M. Medina, P. Savage, \& G.F. Lowe (Eds.), Universalism in public service media. Nordicom, Göteborg Universitet.

Leonardi, P.M. (2012). Materiality, sociomateriality, and socio-technical systems: What do these terms mean? How are they different? Do we need them? In P.M. Leonardi, B.A. Nardi, \& J. Kallinikos (Eds.), Materiality and organizing (pp. 24-48). Oxford University Press. doi:10.1093/acprof: oso/9780199664054.003.0002

Lerner, A., Simpson, A.K., Kohno, T., \& Roesner, F. (2016). Internet Jones and the Raiders of the Lost Trackers: An archaeological study of web tracking from 1996 to 2016. Retrieved from https://www.usenix.org/ conference/usenixsecurity16/technical-sessions/presentation/lerner

Linden, G., Smith, B., \& York, J. (2003). Amazon.com recommendations: Item-to-item collaborative filtering. IEEE Internet Computing, 7(1), 76-80. doi:10.1109/MIC.2003.1167344

Lindskow, K. (2016). Exploring digital news publishing business models: A production network approach. Frederiksberg.

López-Golán, M. (2019). La innovación de las radiotelevisiones públicas europeas en la comunicación digital y las comunidades de usuarios. 16. https://doi.org/10.7764/cdi.45.1350

Löwgren, J., \& Stolterman, E. (2004). Thoughtful interaction design. A design perspective on information technology. The MIT Press. https://doi.org/10.7551/mitpress/6814.001.0001

Lycett, M. (2013). 'Datafication': Making sense of (big) data in a complex world. European Journal of Information Systems, 22(4), 381-386. doi:10.1057/ejis.2013.10 
Milano, S., Taddeo, M., \& Floridi, L. (2019). Ethical aspects of multi-stakeholder recommendation systems. SSRN Electronic Journal. doi:10.2139/ssrn.3493202

Milosavljević, M., \& Vobič, I. (2019). Human still in the loop: Editors reconsider the ideals of professional journalism through automation. Digital Journalism, 7(8), 1098-1116. doi:10.1080/21670811.2019.16015 76

Mitchell, A. (2005). When it comes to media, power is still in the eye of the beholder. Marketing Week, 28(38), 30-31.

Moe, H. (2008). Discussion forums, games and Second Life: Exploring the value of public broadcasters' marginal online activities. Convergence, 14(3), 261-276. doi:10.1177/1354856508091080

Möller, J., Trilling, D., Helberger, N., \& van Es, B. (2018). Do not blame it on the algorithm: An empirical assessment of multiple recommender systems and their impact on content diversity. Information, Communication \& Society, 21(7), 959-977. doi:10.1080/1369118X.2018.1444076

Morgan, D.L. (2008). Snowball sampling. In L.M. Given (Ed.), The SAGE Encyclopedia of Qualitative Research Methods The SAGE encyclopedia of qualitative research methods (pp. 816-817). SAGE Publications, Inc. https://doi.org/10.4135/9781412963909.n425

Murschetz, P.C., \& Prandner, D. (2018). 'Datafying' broadcasting: Exploring the role of Big data and its implications for competing in a big data-driven TV ecosystem. In D. Khajeheian, M. Friedrichsen, \& W. Mödinger (Eds.), Competitiveness in emerging markets (pp. 55-71). Springer International Publishing. doi:10.1007/978-3-319-71722-7_4

Napoli, P. (2011). Exposure diversity reconsidered. Journal of Information Policy, 1, 246. doi:10.5325/jinfopoli.1.2011.0246

Nissen, C.S. (2006). No public service without both public and service: Content provision between the Scylla of populism and the Charybdis of elitism. In C.S. Nissen (Ed.), Making a difference: Public service broadcasting in the European media landscape (pp. 65-82). John Libbey Publishing. https://doi.org/ $10.1057 / 9780230349650.0006$

Olszewski, B., Macey, D., \& Lindstrom, L. (2007). The practical work of <coding>: An ethnomethodological inquiry. Human Studies, 29(3), 363-380. doi:10.1007/s10746-006-9029-2

Pariser, E. (2011). The filter bubble: What the internet is hiding from you. ZNet, 304. doi:10.1353/ pla.2011.0036

Pellegrini, T. (2017). Semantic metadata in the publishing industry: Technological achievements and economic implications. Electronic Markets, 27(1), 9-20. doi:10.1007/s12525-016-0238-x

Pöchhacker, N., Burkhardt, M., Geipel, A., \& Passoth, J.-H. (2017). Interventionen in die Produktion algorithmischer Öffentlichkeiten: Recommender Systeme als Herausforderung für öffentlich-rechtliche Sendeanstalten. Kommunikation@ Gesellschaft, 18, 25.

Pöchhacker, N., Geipel, A., Burkhardt, M., \& Passoth, J.-H. (2018). Algorithmische Vorschlagsysteme und der Programmauftrag: Zwischen Datenwissenschaft, journalistischem Anspruch und demokratiepolitischer Aufgabe. In R.M. Kar, B. Thapa, \& P. Parycek (Eds.), (Un)Berechenbar? Algorithmen und Automatisierung in Staat und Gesellschaft (pp. 417-439). https://www.ssoar.info/ssoar/handle/document/ 57616, https://doi.org/10.15460/kommges.2017.18.2.584

Reith, J.C.W. (1924). Broadcast over Britain. Hodder and Stoughton.

Roesner, F., Kohno, T., \& Wetherall, D. (2012). Detecting and defending against third-party tracking on the web. Paper presented at the 9th USENIX Symposium on Networked Systems Design and Implementation (NSDI 2012) (pp. 12-21). USENIX Association.

Rosen, C. (2004). The age of egocasting. The New Atlantis, Fall 2004/Winter 2005, 51-72. doi:http://www. thenewatlantis.com/publications/the-age-of-egocasting 
Sandvig, C., Hamilton, K., Karahalios, K., \& Langbort, C. (2014). Auditing algorithms: Research methods for detecting discrimination on internet platforms. Paper presented to Data and Discrimination: Converting Critical Concerns into Productive Inquiry, a preconference at the 64th Annual Meeting of the International Communication Association, May 22, 2014, Seattle, WA. Retrieved from http://social. cs.uiuc.edu/ papers/pdfs/ICA2014-Sandvig.pdf

Scannell, P. (2005). The meaning of broadcasting in the digital era. In P. Jauert (Ed.), Cultural dilemmas in public service broadcasting: RIPE@2005 (pp. 129-142). Nordicom.

Schipper, F. (2002). The relevance of Horkheimer's view of the customer. European Journal of Marketing, 36(1/2), 23-35. doi:10.1108/03090560210412683

Schmidt, J.-H., Sørensen, J.K., Dreyer, S., \& Hasebrink, U. (2018). Wie können Empfehlungssysteme zur Vielfalt von Medieninhalten beitragen? Perspektiven für öffentlich-rechtliche Rundfunkanstalten. Media Perspektiven, 11, 522-531.

Schuppan, T. (2009). Reassessing outsourcing in ICT-enabled public management: Examples from the UK. Public Management Review, 11(6), 811-831. doi:10.1080/14719030903318970

Schweizer, C., \& Puppis, M. (2018). Public service media in the 'network' era: A comparison of remits, funding, and debate in 17 countries. In G. F. Lowe, H.V. den Bulck, \& K. Donders (Eds.), Public service media in the networked society RIPE@2017 (pp. 109-124). Nordicom, Göteborg Universitet.

Sommerville, I. (2010). Software engineering. Addison-Wesley. https://doi.org/10.1007/s11616-018-0454-9

Sørensen, J.K. (2011). The paradox of personalisation: Public service broadcasters' approaches to media personalisation technologies. Retrieved from https://www. researchgate.net/publication/295825824_ The_Paradox_of_Personalisation_Public_Service_Broadcasters'_Approaches_to_Media_Personalisation_Technologies, https://doi.org/10.1332/policypress/9781847427601.003.0001

Sørensen, J.K. (2013). PSB goes personal: The failure of personalised PSB web pages. MedieKultur, 29(55), 43-71. Retrieved from http://ojs.statsbiblioteket.dk/index.php/ mediekultur/article/view/7993, https:// doi.org/10.7146/mediekultur.v29i55.7993

Sørensen, J.K. (2019). Public service media, diversity and algorithmic recommendation: Tensions between editorial principles and algorithms in European PSM organizations. CEUR Workshop Proceedings of 7th International Workshop on News Recommendation and Analytics (INRA 2019), 2554, 6-11. Retrieved from http://ceur-ws.org/Vol-2554/paper_01.pdf

Sørensen, J.K. (2020). Personalised universalism in the age of algorithms. Universalism in public service media: RIPE@2019 (pp. 191-205). Nordicom. Retrieved from https://www.nordicom.gu.se/sv/publikationer/universalism-public-service-media

Sørensen, J.K., \& Hutchinson, J. (2018). Algorithms and public service media. In G.F. Lowe, H.V. den Bulck, \& K. Donders (Eds.), Public service media in the networked society RIPE@2017 (pp. 91-106). Nordicom, Göteborg Universitet. Retrieved from http://www.nordicom.gu.se/sites/default/files/publikationer-hela-pdf/public_service_media_in_the_networked_society_ripe_2017.pdf

Sørensen, J.K., \& Schmidt, J.-H. (2016). An algorithmic diversity diet? Questioning assumptions behind a diversity recommendation system for PSM.

Sørensen, J.K., \& Van den Bulck, H. (2018). Public service media online, advertising and the third-party user data business: A trade versus trust dilemma? Convergence: The International Journal of Research into New Media Technologies, 26(2), 421-447. doi:10.1177/1354856518790203

Sørensen, J.K., Van den Bulck, H., \& Kosta, S. (2020). Stop spreading the data: PSM, trust and third-party services. Journal of Information Policy.

Sunstein, C.R. (2001). The daily we: Is the internet really a blessing for democracy? Retrieved from http:// bostonreview.net/forum/cass-sunstein-internet-bad-democracy

Sunstein, C.R. (2007). Republic.com 2.0. Princeton University Press. 
Syvertsen, T. (2003). Challenges to public television in the era of convergence and commercialization. Television \& New Media, 4(2), 155-175. doi:10.1177/1527476402250683

Tadayoni, R., \& Skouby, K.E. (1999). Terrestrial digital broadcasting: Convergence and its regulatory implications. Telecommunications Policy, 23(2), 175-199. doi:10.1016/S0308-5961(98)00086-X

Thurman, N., \& Schifferes, S. (2012). The future of personalization at news websites. Journalism Studies, 13(5-6), 775-790. doi:10.1080/1461670X.2012.664341

Tidline, T.J. (1999). The mythology of information overload. Library Trends, 47(3), 487-506. http://search. ebscohost.com/login.aspx?direct=true \&db=aph\&AN=1848983 \&site=ehost-live

Tiedge, J.T., \& Ksobiech, K.J. (1986). The 'lead-in' strategy for prime-time TV: Does it increase the audience? Journal of Communication, 36(3), 51-63. doi:10.1111/j.1460-2466.1986.tb01437.x

Tintarev, N., \& Masthoff, J. (2015). Explaining recommendations: Design and evaluation. In F. Ricci, L. Rokach, \& B. Shapira (Eds.), Recommender systems handbook (pp. 353-382). Springer US. doi:10.1007/978-1-4899-7637-6_10

Tkalcic, M., \& Chen, L. (2015). Personality and recommender systems. In F. Ricci, L. Rokach, \& B. Shapira (Eds.), Recommender systems handbook (pp. 715-739). Springer US. Retrieved from http://link.springer. com/10.1007/978-1-4899-7637-6_21

UNESCO. (2001). Public broadcasting. Why? How? (pp. 1-28). UNESCO. Retrieved from http://unesdoc. unesco.org/images/0012/001240/124058eo.pdf

Van den Bulck, H., \& Moe, H. (2018). Public service media, universality and personalisation through algorithms: Mapping strategies and exploring dilemmas. Media, Culture \& Society, 40(6), 875-892. doi:10.1177/0163443717734407

Wieringa, M. (2020). What to account for when accounting for algorithms: A systematic literature review on algorithmic accountability. Proceedings of the 2020 Conference on Fairness, Accountability, and Transparency (pp. 1-18). ACM. doi:10.1145/3351095.3372833

Zanitti, M., Kosta, S., \& Sørensen, J. (2018). A user-centric diversity by design recommender system for the movie application domain. Companion of the Web Conference 2018 WWW'18 (pp. 1381-1389). ACM Press. doi:10.1145/3184558.3191580

Zarsky, T. (2013). Transparent predictions. University of Illinois Law Review, 2013(4), 1503-1569.

Zhang, F. (2008). Research on recommendation list diversity of recommender systems. 2008 International Conference on Management of E-Commerce and e-Government (pp. 72-76). IEEE. doi:10.1109/ ICMECG.2008.32

Zuboff, S. (2019). 'We make them dance': Surveillance capitalism, the rise of instrumentarian power, and the threat to human rights. In R.F. Jørgensen \& D. Kaye (Eds.), Human rights in the age of platforms (pp. 3-51). MIT Press. https://doi.org/10.7551/mitpress/11304.003.0006

Jannick Kirk Sørensen

Department of Electronic Systems Aalborg University 